\title{
Minimally Invasive Surgery for Skull Base Tumors
}

\author{
James J. Evans MD \\ Thomas Jefferson University \\ Marc R. Rosen MD \\ Thomas Jefferson University
}

Follow this and additional works at: https://jdc.jefferson.edu/jhnj

Part of the Neurology Commons

\section{Let us know how access to this document benefits you}

\section{Recommended Citation}

Evans MD, James J. and Rosen, Marc R. MD (2008) "Minimally Invasive Surgery for Skull Base Tumors," JHN Journal: Vol. 4 : Iss. 2 , Article 8.

DOI: https://doi.org/10.29046/JHNJ.004.2.004

Available at: https://jdc.jefferson.edu/jhnj/vol4/iss2/8

This Article is brought to you for free and open access by the Jefferson Digital Commons. The Jefferson Digital Commons is a service of Thomas Jefferson University's Center for Teaching and Learning (CTL). The Commons is a showcase for Jefferson books and journals, peer-reviewed scholarly publications, unique historical collections from the University archives, and teaching tools. The Jefferson Digital Commons allows researchers and interested readers anywhere in the world to learn about and keep up to date with Jefferson scholarship. This article has been accepted for inclusion in JHN Journal by an authorized administrator of the Jefferson Digital Commons. For more information, please contact: JeffersonDigitalCommons@jefferson.edu. 


\section{Minimally Invasive Surgery for Skull Base Tumors}

\author{
James J. Evans, $\mathrm{MD}^{1}$ and Marc R. Rosen, MD ${ }^{2}$ \\ 'Department of Neurological Surgery and ${ }^{2}$ Department of Otolaryngology-Head and Neck \\ Surgery Thomas Jefferson University, Philadelphia, Pennsylvania
}

The Jefferson Center for Minimally Invasive Cranial Base Surgery and Endoscopic Neurosurgery reflects three of the current evolutions in neurological surgery. The first of these is reflected in the name of the Center itself. Surgical Procedures, Minimally Invasive, a Medline Subject Heading since 1998, is defined as:

Procedures that avoid use of open invasive surgery in favor of closed or local surgery. These generally involve use of laparoscopic devices and remote-control manipulation of instruments with indirect observation of the surgical field through an endoscope or similar device. With the reduced trauma associated with minimally invasive surgery, long hospital stays may be reduced with increased rates of short stay or day surgery.

Traditionally, cranial base tumors have been removed by making craniotomies or cranial base ostomies, and possibly by removing facial bones. To access these areas, surgeons usually need to make potentially disfiguring incisions in the face and scalp. Sometimes the morbidity from the "open" cranial base approach alone could be significant, even with an uneventful removal of the tumor.

At the Center, the endoscopic approaches are usually through the nose or nasal passages (Figure 1), however transoral endoscopic approaches to the cranial base and cervical spine are also performed. Because morbidity from the minimally invasive endoscopic approaches is so low, it becomes possible to treat patients with tumors that were previously considered non-resectable or as having too poor a prognosis for more invasive surgery. Even partial resection of such tumors can relieve pain, preserve function, and permit earlier adjuvant radiation and chemotherapy.

James Evans, MD and Marc Rosen, MD, both faculty at Jefferson Medical College of Thomas Jefferson University (Evans in Neurological Surgery, Rosen in Otolaryngology-Head and Neck Surgery), are the Center's co-directors. Their collaboration represents another evolution, the increasing interaction between medical and surgical disciplines (Figure 2). Both specialties bring unique instruments, surgical techniques, and clinical experience that have been merged to exponentially increase our understanding and management of cranial base tumors and disorders. Treatment of these patients in the Center also draws upon knowledge and resources from many other departments including Radiology, Oncology, and Ophthalmology.

The third evolution is in the tracking of patient outcomes. Through the Center, we have developed a specialized database for tracking patient demographics, neurological examinations, ENT parameters, endocrine function, ophthalmologic evaluations, tumor control, morbidity, and outcomes. Data collection is essential for confirmation of treatment efficacy and safety. Continual re-evaluation of the treatment process and results can be critical when developing and validating new endoscopic techniques. Also, the "Pay for Performance" movement is a recent addition to the reasons why clinical organizations need to collect and store data that can be searched and cross-referenced. Data at our Center is stored and retrieved using a Microsoft Access database application designed in-house (Figures 3 and 4). With five years of accumulated data, the Center is now getting a clear view of what it has achieved and what the next goals should be.

Many of the Center's patients present with pituitary tumors. Pituitary adenomas represent one of the most common brain tumors and were the first type of tumor where endonasal endoscopic techniques were used. Sixty percent of the patients seen by the Center for such tumors present with visual deterioration. A recent study published by members of our Center has shown that ophthalmologic
Table 1. Advantages of Endoscopic Surgery over "Open" Surgery Better preservation of function and appearance

Lower morbidity rates

Shorter hospital stays

Greater resections of tumors

Facilitates re-operations

Permits earlier post-operative radiation and chemotherapy

studies such as optical coherence tomography not only document the extent of presenting visual loss, but may be used as a predictor of visual improvement with resection of the tumor and decompression of the optic chiasm.

Another area of interest in our Center is the extension of cranial base approaches to include tumors involving the cervical spine. Figure 1 shows an endoscopic transnasal view of the posterior pharyngeal wall and accompanying intraoperative navigation images. We have recently completed a morphometric study on over 100 patients to determine the factors that affect the extent of cervical spine access via an endonasal surgical approach. These findings have led to the development of new techniques and instruments for endonasal cervical spine surgery.

Endoscopic transnasal procedures continue to benefit from technological developments such as real-time intraoperative imaging (MRI, CT), dedicated endoscopic surgical suites, and the development of new materials and techniques for cranial base repair. We are also exploring the adaptation of surgical robotics systems to augment the precise and delicate nature of these endonasal surgical procedures. 

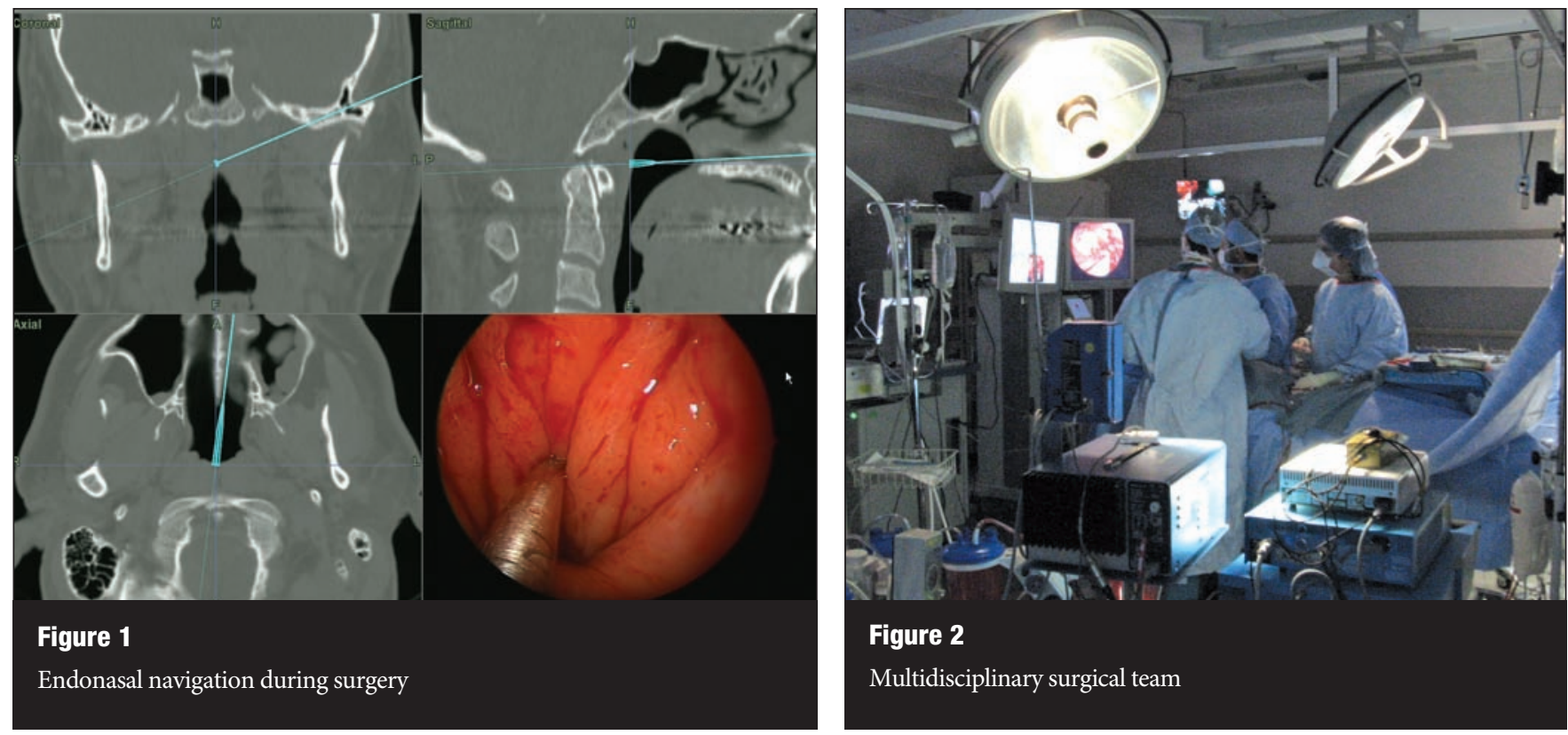

\section{Figure 2}

Multidisciplinary surgical team

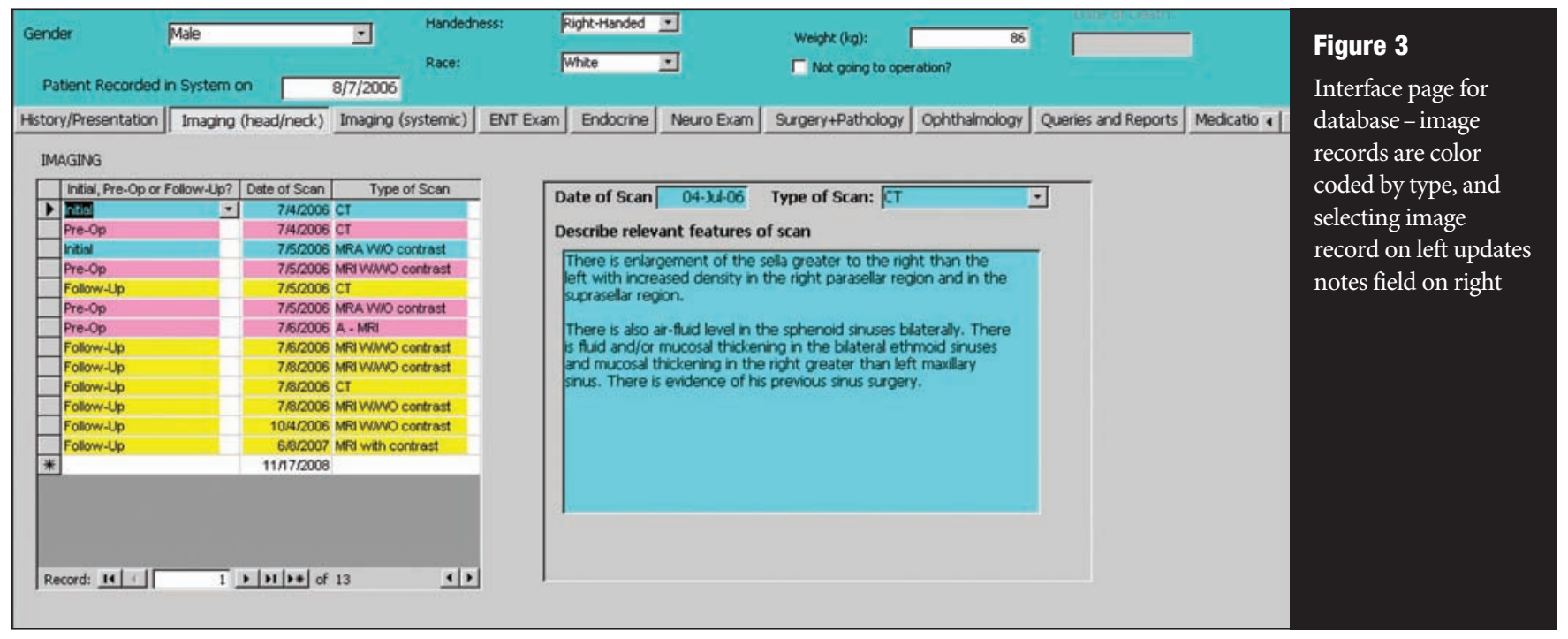

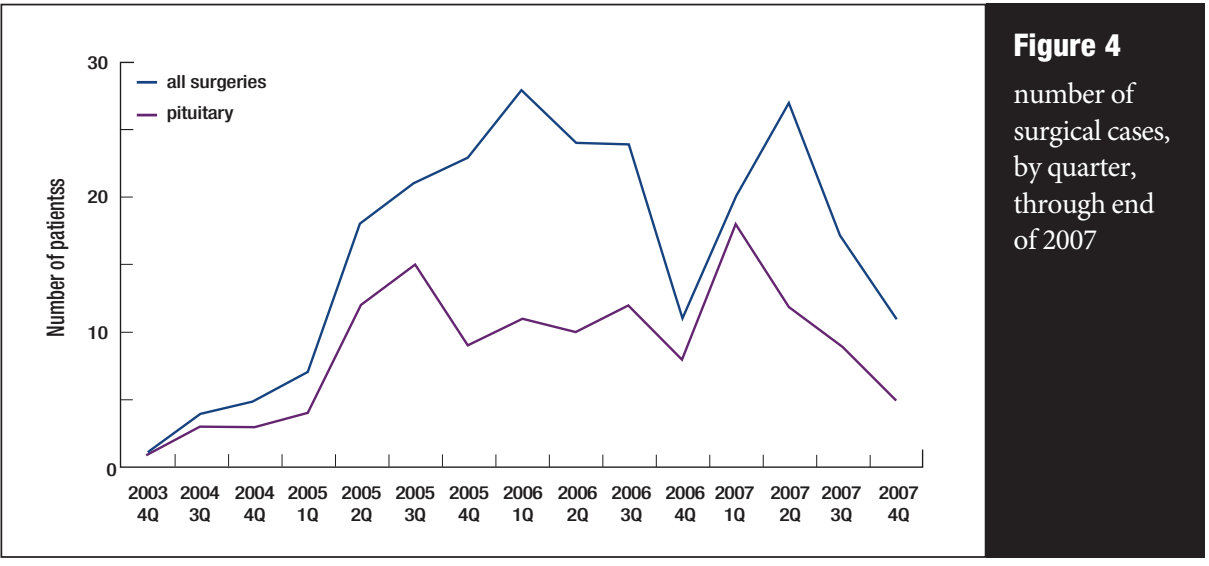

